И.Н. Нурмеев ${ }^{1,2}$, Л.Ф. Рашитов ${ }^{1}$

${ }^{1}$ Детская республиканская клиническая больница, Казань

2 Казанский государственный медицинский университет

\title{
Проблема постоянного
}

\section{сосудистого доступа у больных}

\section{с врожденной комбинированной}

патологией системы свертывания

\section{с тромбогеморрагическим синдромом (случай из практики)}

Contacts:

II'dar Nurmeyev, Doctor of Medical Science, assistant of chair of pediatric surgery of the Kazan State Medical University Address: Orenburg Ride, 130, Kazan, 420138, Tel.: (843) 267-89-69, (843) 269-47-28, e-mail: nurmeev@gmail.com Article received: 01.07 .2012 , Accepted for publication: 03.08 .2012

Лечение пациентов с врожденной комбинированной патологией системы свертывания с тромбогеморрагическим синдромом сопровождается рядом трудностей, одной из которых является необходимость в постоянном сосудистом доступе для обеспечения адекватной патогенетической терапии. В статье приводится случай из практики, иллюстрирующий проблематику поиска путей обеспечения постоянного сосудистого доступа у больного с врожденным комбинированным дефицитом витамин К-зависимых факторов свертывания (II, VII, IX, X, S и C-белков) и тяжелым течением тромбогеморрагического синдрома.

Ключевые слова: патология системы свертывания, постоянный сосудистый доступ, тромбогеморрагический синдром.

Врожденная патология системы свертывания включает в себя несколько отдельно описанных заболеваний, различающихся по преимущественному поражению различных ее компонентов и направленности изменений. Они подразделяются на снижение свертывающей способности крови (гипокоагуляцию) и ее повышение (гиперкоагуляцию) локального или генерализованного характера [1].
Наиболее трудны для диагностики и лечения комбинированные формы дефицита плазменных факторов свертывания крови.

Среди множества коагулопатий известно 2 заболевания, которые связаны с комбинированным дефицитом витамин-К-зависимых факторов свертывания крови:

1) недостаточность плазменных факторов свертывания множественная (№ 277450 в базе Online

I.N. Nurmeyev ${ }^{1,2}$, L.F. Rashitov ${ }^{1}$

${ }^{1}$ Children Republican Clinical Hospital, Kazan

2 Kazan State Medical University

\section{The problem of permanent vascular access in patients with congenital combined coagulation disorder and thrombohemorrhagic syndrome (a clinical case)}

Treatment of patients with congenital combined coagulation disorder and thrombohemorrhagic syndrome is associated with a number of difficulties, one of them is need of permanent vascular access in order to provide appropriate pathogenetic therapy. The article contains a clinical case, representing a subject matter of searching for means of providing a permanent vascular access in a child with congenital combined deficiency of vitamin K dependent clotting factors (II, VII, IX, X, S- and C-protieins) and severe course of thrombohemorrhagic syndrome.

Key words: coagulation disorder, permanent vascular access, thrombohemorrhagic syndrome. 
Mendelian Inheritance in Man [OMIM]), витамин К-зависимый коагуляционный дефект, аутосомнорецессивное наследование [2];

2) комбинированный дефицит витамин-К-зависимых факторов свертывания крови (№ 607473 в ОМІМ) - редкое заболевание с аутосомно-рецессивным типом наследования, вызываемое мутациями в гене VKORC1 [3].

Врожденный дефицит витамин-К-зависимых факторов затрагивает как свертывающую (факторы II, VII, IX и X), так и антикоагулянтную систему (протеины S и C). B результате заболевание манифестирует геморрагическим синдромом в комбинации с тромбообразованием.

В литературе имеются описания единичных случаев такого комбинированного дефицита $[4,5]$.

Ниже приводится собственный опыт курации пациента с врожденной комбинированной патологией системы свертывания с тромбогеморрагическим синдромом. Хирургическое внимание к пациенту обусловлено

Рис. Схема установки имплантируемого катетера

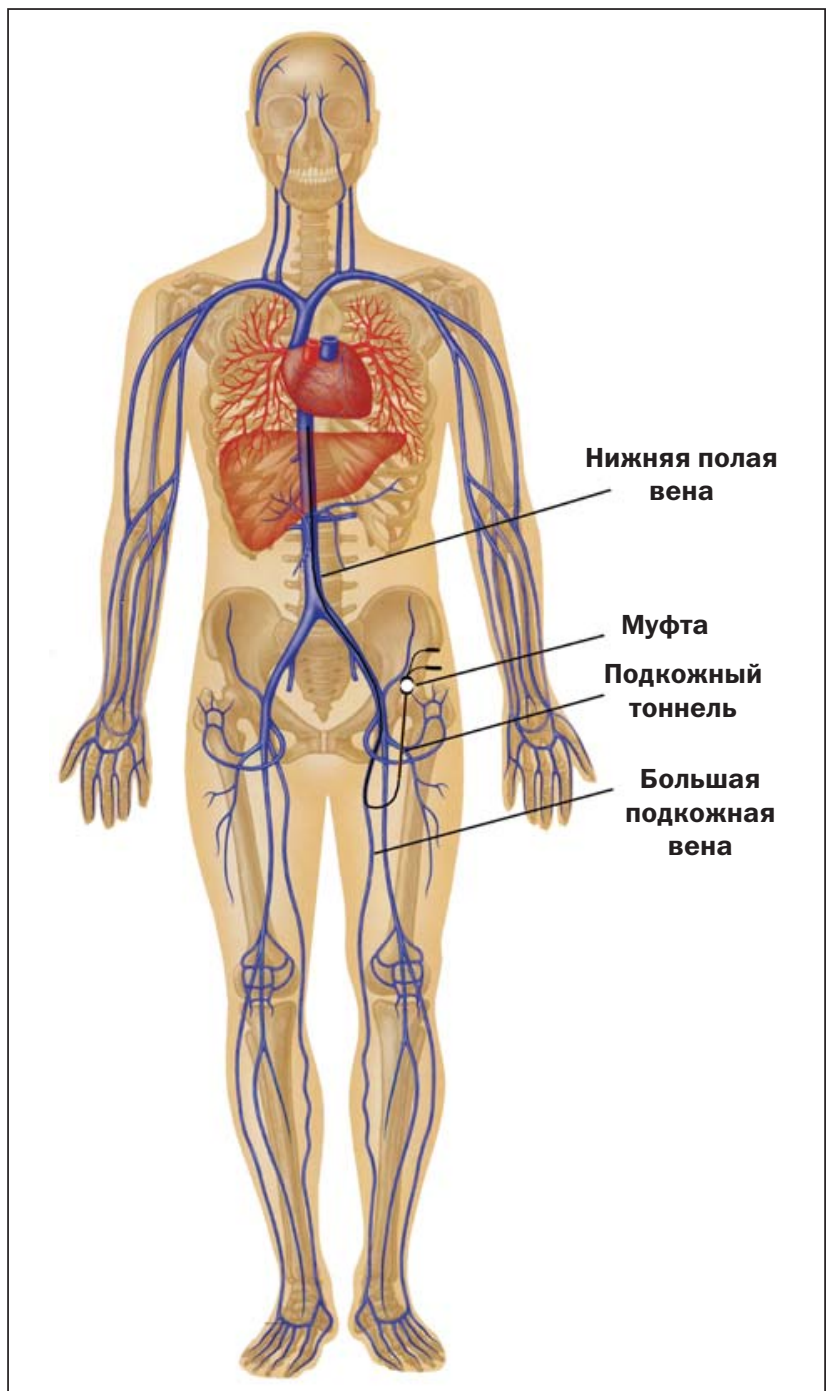

Примечание. Катетер установлен в бедренной вене, сформирована петля на бедре, катетер через подкожный тоннель проведен в подвздошную область и выведен наружу. Вблизи вывода концов катетера на кожу в подкожной клетчатке располагается муфта для дополнительной фиксации катетера к окружающим тканям. необходимостью обеспечения постоянного сосудистого доступа [6].

Больной Я., 14 лет, поступил в ДРКБ Министерства здравоохранения Республики Татарстан для формирования постоянного сосудистого доступа в связи с необходимостью ежедневной инфузии препаратов факторов свертывания и гепарина.

Диагноз: “Врожденный комбинированный дефицит витамин-К-зависимых факторов свертывания (II, VII, IX, $\mathrm{X}, \mathrm{S}$ и С-белков). Тромбогеморрагический синдром, тяжелое течение. Системный остеопороз, остеохондропатия тел $\mathrm{L}_{1-2}, \mathrm{Th}_{9-12}$ позвонков. Хронический тубулоинтерстициальный нефрит, без нарушения функции почек. Поливалентная пищевая и лекарственная аллергия".

Из анамнеза: пациент болен с рождения, когда появились признаки геморрагического синдрома в виде рецидивирующей кефалогематомы. В возрасте 40 дней впервые был госпитализирован по поводу профузного носового кровотечения. В последующем геморрагический синдром проявлялся в виде носовых и желудочнокишечных кровотечений, в связи с чем ребенок был неоднократно обследован и получал лечение по поводу геморрагического синдрома. Диагноз поставлен и подтвержден в Измайловской больнице г. Москвы, где пациент проходил обследование в 2004 и 2009 гг. Впоследствии была назначена заместительная терапия препаратами протромбинового комплекса по витальным показаниям (ежедневное внутривенное введение).

Для обеспечения постоянного венозного доступа многократно выполнялись катетеризации яремных и подключичных вен с обеих сторон. В течение двух последних лет функционировал двухпросветный катетер типа BROVIAC, установленный в правую внутреннюю яремную вену. Постоянно проводилась профилактика тромбоза препаратами гепарина, алтеплазой, урокиназой. В последний месяц возникли трудности в работе указанного венозного катетера: отсутствие тока внутрь в одном из его просветов, работа только на вход второго просвета, болевые ощущения в месте введения катетера.

На момент поступления пациента: состояние средней степени тяжести за счет умеренного геморрагического синдрома. Наружных кровотечений не обнаружено. На коже имелись единичные экхимозы различной степени давности. Слизистые оболочки чистые. Суставы не изменены, движения в них в полном объеме. Стул оформленный, без патологических примесей.

С целью обеспечения безопасности имплантации катетера была рекомендована заместительная терапия факторами свертывания крови II, VII, IX И X в комбинации (протромбиновый комплекс), которая проводилась в дозе 1200 ME до и после операции и в дальнейшем по 1200 ME каждые 6 ч.

В рамках предоперационного обследования и выбора области имплантации катетера в отделении сердечнососудистой хирургии ДРКБ было проведено ультразвуковое исследование. По данным УЗИ выявлен посттромботический синдром с окклюзией яремных и подключичных вен с обеих сторон. Согласно полученным данным, традиционный доступ в систему верхней полой вены невозможен. В то же время была подтверждена сохранность под- 
вздошных вен с обеих сторон. Коллегиально было решено установить катетер в систему нижней полой вены.

Мальчик развит по возрасту, повышенного питания, активен. Ежедневно выполняет пешие прогулки по 2-3 км, упражнения на мышцы брюшного пресса. Традиционная установка имплантируемого катетера с выводом наружных концов на бедре была исключена ввиду высокой активности пациента.

Ребенку была проведена операция: имплантация катетера BROVIAC Lifecath expert $5 \mathrm{fr} 75 \mathrm{~cm}$. Катетер установлен в просвет левой бедренной вены с формированием подкожного тоннеля и выводом внешних концов на кожу левой подвздошной области (рис.). Установка имплантируемых катетеров требует выполнения трех разрезов кожи: один - для пункции вены, второй в точке перегиба и третий - в месте вывода внешних концов. Пункция вены осуществлена вблизи сафенофеморального соустья открытым способом, через операционный доступ (разрез) на бедре. Интраоперационный рентгенологический контроль положения рентгенокон- трастного проводника показал расположение последнего в просвете нижней полой вены. Путем выполнения верхнего разреза кожи на животе введен катетер, который далее проведен в тоннеле в подкожной клетчатке до необходимого уровня на бедро, немного ниже первого доступа. В указанной точке выполнен второй разрез кожи, сформирована петля для смены направления катетера с нисходящего на восходящее. Катетер по проводнику установлен в просвет вены. В катетерах такого типа за несколько сантиметров до вывода на кожу располагается муфта, впоследствии врастающая в окружающую жировую клетчатку, что затрудняет свободное движение катетера даже при существенных натяжениях (см. рис.). На операционные разрезы наложены узловые швы нитью 5/0, которые были сняты спустя 10 дней.

Таким образом, приведенное наблюдение демонстрирует имеющиеся технические сложности и возможности реализации постоянного сосудистого доступа у больных с врожденной комбинированной патологией системы свертывания с тромбогеморрагическим синдромом.

\section{REFERENCES}

1. Dement'yeva I.I., Charnaya M.A., Morozov Yu.A. Patologiya sistemy gemostaza [Pathology of Hemostasis System]. M.: GEOTARMedia. 2011. 283 p.

2. URL: http://omim.org/entry/277450

3. URL: http://omim.org/entry/607473

4. Brenner B., Tavori S., Zivelin A. et al. Hereditary deficiency of all vitamin K-dependent procoagulants and anticoagulants. Brit. J. Haemat. 1990; 75: 537-542.

5. Oldenburg J., von Brederlow B., Fregin A. et al. Congenital deficiency of vitamin $\mathrm{K}$ dependent coagulation factors in two families presents as a genetic defect of the vitamin K-epoxide-reductase-complex. Thromb. Haemost. 2000; 84: 937-941.

6. Gematologiya: Noveyshiy spravochnik [Hematology: The Latest Reference Book]/End. by Abdulkadyrova K. M. M.: Izd-vo "Eksmo"; SPb.: Izd-vo "Sova". 2004. 928 p., ill. 